\title{
Peculiarities of the Vertical Thermal Regime of Lake Tapeliai
}

\author{
Paulius Miškinis ${ }^{1,2}$, Anastasija Moisejenkova ${ }^{1,2}$, Artūras Jukna ${ }^{1,2}$, \\ Vaida Vasiliauskiené2 ${ }^{2}$ Gražina Grigaliūnaitė-Vonsevičienè ${ }^{2}$, \\ Asta Daunaravičiene் $\dot{e}^{2}$ \\ ${ }^{1}$ Laboratory of Photovoltaic Technology VGTU, Vilnius, Lithuania \\ ${ }^{2}$ Department of Physics, Faculty of Fundamental Sciences, Vilnius Gediminas Technical University, \\ Vilnius, Lithuania
}

Received: 16 April 2018

Accepted: 2 August 2018

\begin{abstract}
A nonlinear model of temperature dependence on lake depth is proposed for interpreting the vertical thermal structure of a lake. The model has two critical temperatures: $T_{1}^{*}$ - the maximum density water temperature $T_{c r}=4^{\circ} \mathrm{C}$ and $T_{2}^{*}$ - the lake water surface asymptotic temperature in warm seasons. Although the model depends on four parameters, its solution and properties are effectively determined by only two dimensionless parameters: the constant temperature gradient $\gamma$ and the nonlinearity parameter $v$. The proposed thermodepth model is applicable to the interpretation of the vertical thermal regime of Lake Tapeliai by comparing the results of theoretical calculations and experimental measurements. Within the limits of our model, the position of the thermocline can be determined theoretically, i.e., the model parameters allow for expressing the thermocline position. A great match has been obtained between experimental data and theoretical dependencies.
\end{abstract}

Keywords: lake, thermal regime, thermocline, modelling

\section{Introduction}

One of the basic parameters of lake water is temperature $[1,2]$. The willingness to determine the thermal structure theoretically applicable to the biggest variety of lakes drives professionals to create quite complex software packages taking into account all possible internal and external factors that determine lake water temperature changes [3-5]. Mathematically, such software packages comprise 9-15 nonlinear

*e-mail: paulius.miskinis@vgtu.lt differential equations with partial derivatives and border and initial conditions of the same amount. The model has about 10 free parameters, which in principle give a good coincidence with experimental data (see [4-6]).

Determining the lake thermal structure belongs to the classical limnology area and is under investigation up to now (see, e.g., $[28,29]$ and the references therein). Continuous thermodynamic, hydrophysical and other processes allow us to group lakes under selected criteria. Usually, they are classified according to the origin of water sources, water chemical structure, slope, water quality, water level, water circulation intensity, etc. [7-10]. Many works have recently analyzed the 
issues related to lake chemical pollution, thermal and other processes in lake bottom sediments.

There is a lack of information on the modelling of the thermal regime of water. The analysis of lake water thermodynamic thermal regimes in different seasons is relevant. A lake's thermal regime is a key parameter in the physics of water system processes, which in its turn is very important for the course of biotic and abiotic processes occurring in lakes. An increased temperature accelerates the lake biogeochemical and water cycles.

The purpose of this article is to propose a simple one-dimensional mathematical model of the lake vertical thermal structure while applying the model to explain the thermal structure of a certain lake (the Tapeliai) in order to define the theoretical values and depth of its thermolimnion and to compare them with experimental data.

\section{Materials and Methods}

\section{Object of the Study}

Lake Tapeliai $\left(54^{\circ} 46^{\prime} 28^{\prime \prime} \mathrm{N}, 2^{\circ} 26^{\prime} 45^{\prime \prime} \mathrm{E}\right)$ is located $17 \mathrm{~km}$ northeast of Vilnius, Lithuania, in a wooded region at $136.1 \mathrm{~m}$ a.s.1. (Fig. 1). It is the initial water body in a lake chain connected by a brook. The lake is eutrophic. Its banks are rushgrown with a marshy zone formed at a brook outflow area.

The basin of the lake is of a glacier origin and consists of four parts: 1) the shallow southern terrace

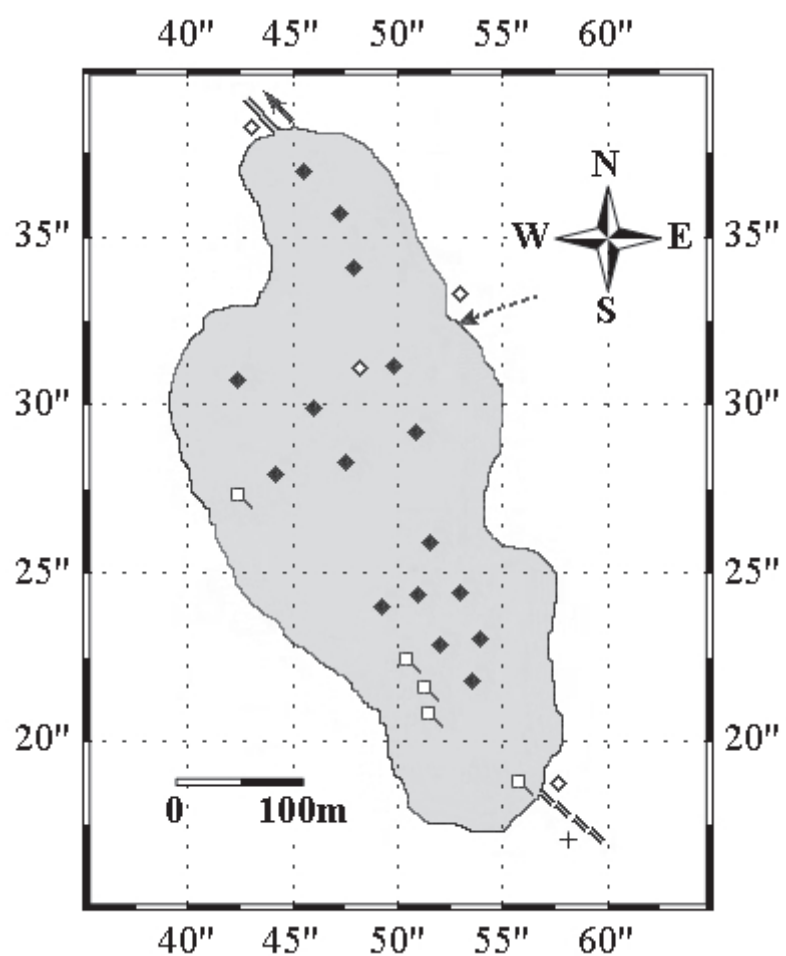

Fig. 1. Scheme of Lake Tapeliai: $(\downarrow)$ sampling sites of sediment cores, $(\diamond)$ water sampling sites, (․) location of bottom feeding sources, $(+)$ old channel. (depth $4-5 \mathrm{~m})$; 2) the central deeper part of the lake (depth 7-9 m); 3) the northern terrace with a constantly changing bottom (the depth varies from $1.5 \mathrm{~m}$ to $6 \mathrm{~m}$ ); and 4) a small basement terrace on the west side of the lake (depth 5-6 m). It has also been found that along with the watershed, the lake is fed by bottom-feeding sources located in three different zones: a) near the western coast of the southern terraces at a depth of about 4-4.5 m; b) in the southwestern zone of the central part of the lake area; c) at the southern edge of the lake near the old drainage channel which previously combined the Tapeliai and the Lydekinis (Red) lakes. They are located in distinct areas marked in Fig. 1 by the symbol "a".

During flood periods (in spring and after long-term rains), the lake is additionally fed (sometimes for some months) by a temporal discharge with colored water (shown by a dotted arrow, Fig. 1) from a swamp.

The surface area of the lake is equal to $\sim 0.131 \mathrm{~km}^{2}$, its drainage basin is $\sim 0.7 \mathrm{~km}^{2}$ [11], the mean depth $\sim 3.3 \mathrm{~m}$, the water retention time $\sim 1$ year. The typical amount of dry substances in the surface layer of the sapropelic-type sediments in the lake mainly varies in the range of 20-36 g/L. The organic content of the sediments, determined as a loss on ignition, is shown to increase with sediment depth (down to $30-35 \mathrm{~cm}$ ) and varies in the range of 50-70\% (the southern platform). The thickness of the sediment layer measured in the northern terrace increases with the bottom depth. It varies from $\sim 1.5 \mathrm{~m}$ near the northern rush-grown bank up to $\sim 4 \mathrm{~m}$ at a depth of $6 \mathrm{~m}$. The concentrations of total dissolved solids (TDS) in the lake water, determined on evaporation (dry deposits), are mainly in the range of $180-220 \mathrm{mg} / \mathrm{L}$.

\section{Parameterization}

The vertical profiles of the water temperature were episodically measured in a lake water column from July 2006 to February 2011, with a pause from August 2007 until March 2008. The aim of the study was to estimate lake mixing conditions and the seasonal variations of the lake vertical structure. The measurements of the surface temperature were carried out at a depth of $5 \mathrm{~cm}$ in all seasons of the year.

The sediment samples were analyzed for ${ }^{137} \mathrm{Cs}$, using a SILENA $\gamma$-spectrometric system with an HPGe detector (42\% relative efficiency, resolution $1.8 \mathrm{keV} / 1.33$ $\mathrm{MeV}$ ) according to the gamma line at $661.62 \mathrm{keV}$ of ${ }^{137 \mathrm{~m}} \mathrm{Ba}$ (a daughter product of ${ }^{137} \mathrm{Cs}$ ). Measurements were carried out in standard geometry and at known efficiencies according to the densities of samples [11-12].

A portable ProfiLine Multi 197i (WTW) device with $10 \mathrm{~m}$ cables allowed for carrying out these measurements down to the lake bottom. During a warm period, measurements were conducted from an inflatable boat stabilized by an anchor. In winter, holes were drilled in the ice. As a rule, measurements were carried out at the deepest site of the central part of the lake. 


\section{The Thermodepth Model}

It can be shown that from the equation of heat flux balance flows, the change of temperature $T$ at the lake's depth $h$ must satisfy the differential equation and the initial conditions:

$$
\frac{d T}{d h}=a T\left[\left(\frac{T}{T_{c}}\right)^{v}-1\right]+b, \quad T(0)=T_{0}
$$

where $T=T(h)$ is the temperature dependent on the depth, $d T / d h$ the derivative of temperature with respect to depth, $a$ is the constant inversely proportional to the depth of the lake $\left([a]=m^{-1}\right), T$ is the critical temperature $\left([T]={ }^{\circ} \mathrm{C}\right)$ also constant independent by the depth $h$ value $([h]=m), b$ is the constant gradient of temperature $\left([b]={ }^{\circ} \mathrm{C}\right)$, and $v$ is the nonlinearity parameter: positive, real, not necessarily an integer. The depth of the lake changes from $h=0$ on the surface to $h=h_{b}$ at the bottom. $T_{0}$ is the temperature of the surface water of the lake.

The differential equation along with the initial conditions (1) make up a mathematical model of the temperature dependence on the lake depth, which is called the thermodepth model.

The differential equation of model (1) depends on three constant dimensional parameters, $a, b, T$, and one dimensionless parameter $v$. Their consistency is relative: it may depend (and indeed depends) on thermal conductivity, density, and even on time; it is important that the parameters are independent on depth $h$ and temperature $T$.

Mathematically, the differential equation of model (1) is a simple first-order non-homogeneous, nonlinear, ordinary differential equation. In the applications, a homogeneous case of these differential equations with a constant temperature gradient $b=0$ is well known. In the case of $v=1$, this is the well-known logistic or Pierre-François Verhulst equation [13, 14]. In general, when $v \neq 1$, this equation turns into Richard's equation [15], in ecology more commonly known as the $\theta$ - model equation (see, for example, [16] and the references therein). The mathematical meaning of our thermodepth model is more complicated because it is non-homogeneous.

The fact that nonlinear mathematical models are necessary to interpret the thermodepth properties of a lake should not be astonishing. It suffices to recall that the equations of classical hydrodynamics are nonlinear. In addition, various properties of liquids can also be interpreted only by nonlinear phenomena [17].

\section{The Dimensionless Form}

The usual way to find the solution of a mathematical model (1) is to use the numerical methods of solution. As we have already mentioned, the differential equation of the thermodepth model depends on the parameters, therefore, it is necessary to determine the dependence of the solution result on the model parameters. Although the parameters are independent, sometimes the solution depends on a combination of them, which effectively reduces the number of parameters.

One way to reduce the number of independent parameters is the reduction of the model to the dimensionless form. Let us introduce values:

$$
\theta=\frac{T}{T_{c}} ; \quad x=a h ; \quad \gamma=\frac{b}{a T_{c}},
$$

where $\theta$ is the dimensionless temperature, $x$ is the dimensionless depth, and $\gamma$ is constant dimensionless temperature gradient. After the change of variables (2), the mathematical thermodepth model (1) acquires a dimensionless form:

$$
\frac{d \theta}{d x}=\theta\left(\theta^{v}-1\right)+\gamma ; \quad \theta(0)=\theta_{0}
$$

The results given by the differential equation of thermodepth model (1) depend on four parameters, $a, b, T_{c}$ and $v$, but dimensionless differential equation of the thermodepth model (3) depends only on two parameters, $\gamma$ and $v$, and they are both dimensionless.

\section{The Thermodepth Portrait}

Considering the thermodepth model (1) as evolutionary, we can adapt the dynamical system methods to its mathematical analysis [18].

First, we determine the stationary thermodepth model solutions. For this purpose, we show the temperature gradient's $d T / d h$ dependence on the temperature, i.e., the thermodepth model (1) portrait (see Fig. 2).

As follows from the experimental measurements, the temperature of the deep water layers practically does not depend on the depth, whereas the temperature of the upper water layers under the influence of solar radiation depends on the depth very essentially. This means that the temperature gradient in the deep water layers almost does not change: $d T / d h \approx 0$. Dependence $T(h)$ with this

\section{Temperature, $T\left[{ }^{\circ} \mathrm{C}\right]$}

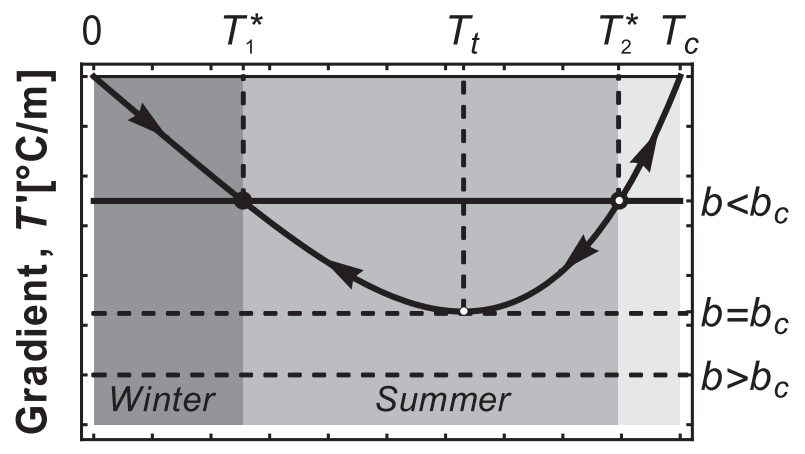

Fig. 2. Thermodepth model portrait. 
property is called stationary solution. It is convenient to turn to the dimensionless form (3) of the thermodepth model.

The solution of the stationary thermodepth model equation (1) when the temperature gradient does not change $d \theta / d x=0$, corresponds to the solution of the equation

$$
\theta\left(\theta^{v}-1\right)+\gamma=0
$$

Depending on the parameter $\gamma$ value, in the interval $0 \leq \theta \leq 1$, equation (4) has two solutions for $\left(0<\gamma<\gamma_{c}\right)$, one solution at $\gamma=\gamma_{c}$ or no solution for $\left(\gamma<\gamma_{c}\right)$, where $\gamma_{c}$ is the critical value of the $\gamma$ parameter when line $\gamma$ touches the curve $y(\theta)=\theta\left(\theta^{v}-1\right)$ at a single minimum point, when $\theta=(1+v)^{-1 / v}$ :

$$
\gamma_{c}=\frac{v}{(1+v)^{\frac{1+v}{v}}}
$$

and depends only on the dimensionless value of the parameter of nonlinearity $v$. Recalling the definition of the $\gamma$ parameter (2), we obtain the critical value of the constant temperature gradient:

$$
b_{c}=\frac{v}{(1+v)^{\frac{1+v}{v}}} a T_{c}
$$

Thus, in the portrait of the thermodepth model (Fig. 2), depending on the value of the $b$ parameter we have two critical temperatures $T_{1}^{*}$ and $T_{2}^{*}$ when $0<b<b_{c}$, one critical temperature $T_{1}^{*}=T_{2}^{*}=T_{t}^{*}$ when $b=b_{c}$, and finally, if $b<b_{c}$, the thermodepth model (1) does not have any stationary critical temperature.

Since the extreme condition $T_{h}^{\prime}=0$ in the dimensionless case corresponds to the condition $\theta_{x}^{\prime}=0$, it results in two critical temperatures $T_{1}^{*}$ and $T_{2}^{*}$ in the thermodepth model (1). Their values are related to the model's critical temperature $T_{c}$. In the case when the nonlinearity parameter $v=1$, the critical temperatures $T_{1}^{*}$ and $T_{2}^{*}$ are expressed by a critical temperature analytically:

$$
T_{1}^{*}=(1-r) \frac{T_{c}}{2}, T_{2}^{*}=(1+r) \frac{T_{c}}{2}, r \equiv \sqrt{1-\frac{4 b}{a T_{c}}}
$$

For applications it is convenient to use the expressions from the formulas (7):

$$
T_{2}^{*}+T_{1}^{*}=T_{c}, \quad T_{2}^{*}-T_{1}^{*}=r T_{c} .
$$

The theoretical temperature dependence on the depth $T(h)$, obtained from the thermodepth model (1), varies in the field of critical temperatures in different ways. As depth $h$ increases, the temperature dependence $T(h)$ approaches the critical temperature $T_{1}^{*}$ and moves to exceed the critical temperature $T_{2}^{*}$. This is related to the stability of the $T(h)$ dependence.

As follows from the general statements of the theory of ordinary differential equations (see, for example, [19]), it is possible to show that the critical temperature $T_{1}^{*}$ is stable and $T_{2}^{*}$ is not. The critical temperature $T_{1}^{*}$ is marked as full-flow and the unstable $T_{2}^{*}$ as hollow points in the termodepth model (1) portrait. The point of minimum $T_{t}$, marked with a small hollow ball, corresponds to the temperature of the thermocline, which has a special part in this publication. The arrows indicate the corresponding variation of $T(h)$ with the increasing depth.

\section{Termodepth Model Solutions}

In general, for any parameter $v$ the solution of the thermodepth model (1) is obtained using only numerical computational methods. However, when $v=1$ in the case of non-homogeneous Verhulst equation, there is a precise analytical solution [20]:

$$
\begin{aligned}
T(h) & =T_{c}\left[\frac{1}{2}-r \operatorname{th}\left(\operatorname{arh}-\varphi_{0}\right)\right], \quad b<b_{c},(9 \mathrm{a}) \\
\varphi_{0} & =\operatorname{arcth}\left(\frac{c}{r}\right) ; \quad c=\frac{T_{0}}{T_{c}}-\frac{1}{2} . \quad(9 \mathrm{~b})
\end{aligned}
$$

When the nonlinearity parameter $v \neq 1$, a good approach is an analytical solution of Richard's equation, proposed in [21]:

$$
T(h)=T_{1}^{*}+\frac{T_{2}^{*}-T_{1}^{*}}{\left(1+a_{0} e^{v / h}\right)^{1 / v}} ; a_{0}=\left(\frac{T_{2}^{*}}{T_{0}}\right)^{v}-1, T_{1}^{*}<T_{0}<T_{2}^{*} .
$$

These two analytical solutions (9) and (10) allow us to avoid complicated numerical methods and go straight to the approximation of experimental data.

In the case of different initial conditions, the general form of the solution is shown in Fig. 3. The properties of the solutions indicate that the first critical temperature $T_{1}^{*}$ correlates with the maximum density water temperature $\mathrm{T}_{c r}=3.984{ }^{\circ} \mathrm{C}\left(39.16^{\circ} \mathrm{F}\right)$, when the water density becomes the highest: $\rho_{c r}=999.972 \mathrm{~kg} / \mathrm{m}^{3}$ [22], and $T_{2}^{*}$ corresponds to the asymptotic temperature of the water surface of the lake in the warm season. An additional "richer" structure occurs due to additional layering phenomena (see, for example, [23] and references therein).

As seen in the portrait of the thermodepth model (Fig. 2), a stable temperature is marked with appropriate beads at the edge of the graph: full-flow for temperature $T_{1}^{*}$ and hollow for temperature $T_{2}^{*}$. The position of the thermocline is depicted at depth $h_{t}$, with a hollow ball. Two seasons are marked in the graph: the summer "s" is the central vertical area of the graph from $T_{1}^{*}$ 


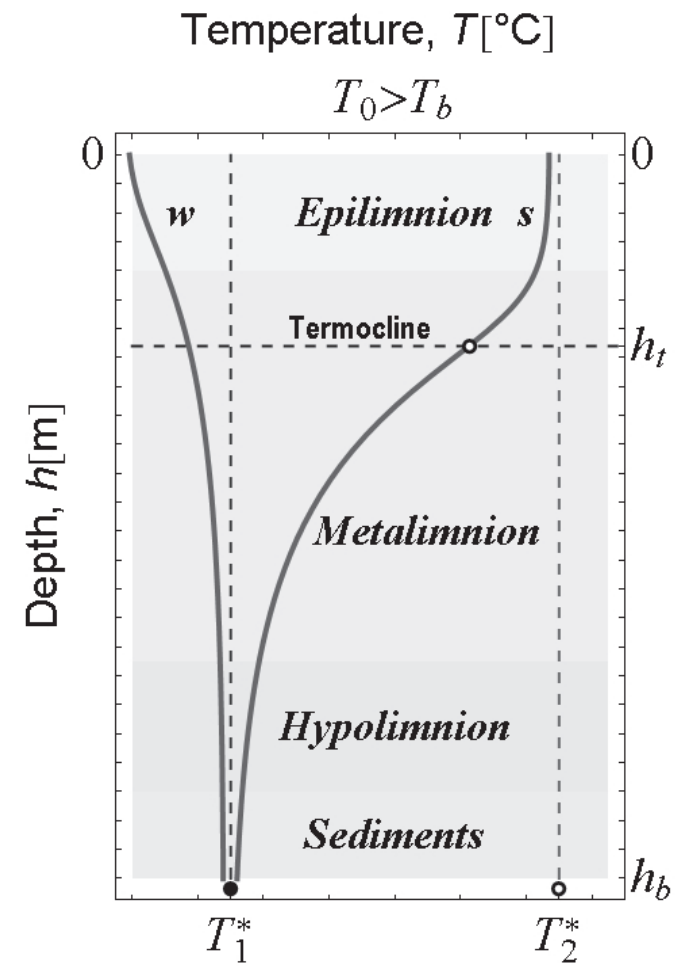

Fig. 3. General dependence of the vertical thermal regime $T(h)$ determined as the solution of the theoretical thermodepth model.

to $T_{2}^{*}$, and the winter "w" is the left vertical part of the graph from $T=1$ to $T_{1}^{*}$. In summer, the surface temperature is higher than the bottom temperature of the lake: $T_{0}>\mathrm{T}$, while the winter is the opposite situation: $T_{0}<\mathrm{T}_{b}$.

\section{Approximation of Experimental Results}

Complex bathymetric measurements of Lake Tapeliai associated with sediments have been published [24]. In the present work, we will use at the same time our obtained experimental results concerning the temperature dependence on depth.

The data of temperature measurements made on May 31 represents Fig. 4. Seeking to receive the best possible correspondence with the experiment data, three areas of measurement data were separated: 1) the basic data sequence, 2) the second epilimnion [25], and 3) the sediments area. The total approximation function $T(h)$ is represented as the sum of three functions:

$$
T(h)=T_{1}+T_{2}+T_{3},
$$

where $T_{i}=T_{i}(h), i=1,2,3$, and the approximations are performed in each area separately. Using the mathematical package Mathematica 4.0 [License L2990-7548] or any other package which is able to do it, after approximations we will get the corresponding coefficient values.

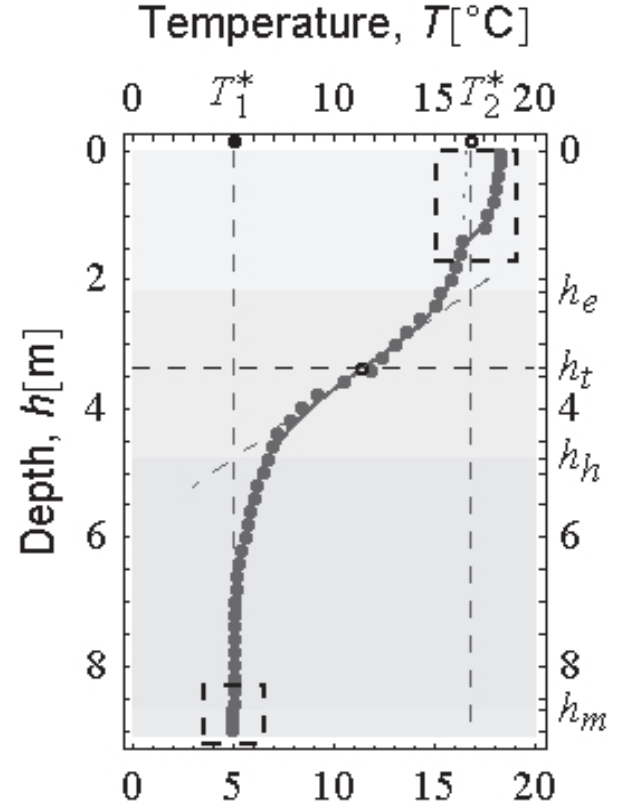

Fig. 4. Approximation of the vertical thermal regime $T(h)$ of experimental data; the thermocline position is marked with a circle.

In our case, the three functions look like this:

$$
\begin{gathered}
T_{1}=\frac{11.47}{\left(1+2.95 \cdot 10^{-3} \mathrm{e}^{0.01872 \cdot h}\right)^{0.6234}}+5.054 . \\
T_{2}=\frac{1.454}{\left(1+9.45 \cdot 10^{-5} \mathrm{e}^{0.0550 \cdot h}\right)^{9.091}}+0.136 . \\
T_{3}=-\frac{0.09}{1+\mathrm{e}^{865-\mathrm{h}}}-0.08 .
\end{gathered}
$$

With a small amount of data in the area of the secondary thermocline of the epilimnion and sediments, these data were approximated by selecting the nonlinear parameter value $v=1$.

Our research of dependence consists of only three areas. However, according to our and other researchers' results, the thermodepth addiction can be much more complicated (see, e.g., [2-6]). The subtlety of the $T(h)$ dependence may be explained by second thermoclines (see, e.g., [25]). In our model, this would mean a greater number of domains and approximation functions.

In the approximation of experimental data, we found the critical temperatures $T_{1}^{*}$ and $T_{2}^{*}$, the constant values $a$ and the non-linearity parameter $v$. The thermodepth portrait can be used to determine the remaining two parameters: $T_{c}=10.19{ }^{\circ} \mathrm{C}$ and $b=5.255 \cdot 10^{-2}{ }^{\circ} \mathrm{C} / \mathrm{m}$. Formula (6) allows to determine the critical value of the constant temperature gradient $b_{c}=7.994 \cdot 10^{-2}{ }^{\circ} \mathrm{C} / \mathrm{m}$. As it should be, there are two critical temperatures $T_{1}^{*}$ and $T_{2}^{*}$ when $b<b_{c}$. Correspondingly, in the dimensionless case, the critical value of the $\gamma_{c}$ parameter (5) is $\gamma_{c}=0.339207$, whereas when the $\gamma$ value used 
in the model is determined by formula (2), there is $\gamma=0.22299$, which also confirms the condition $\gamma<\gamma_{c}$.

The maximum deviation of the theoretical dependence from the experimental values is at the depth of about $4 \mathrm{~m}$ at a temperature of $8{ }^{\circ} \mathrm{C}$. The numerical depth and temperature deviations allow for estimating the approximation inaccuracy, which is about $2.5 \%$. Correspondingly, this means that the model's correctness is about $97.5 \%$, which indicates the excellent coincidence between the model and the experimental data.

\section{Position of the Thermocline}

Prof. R. Wetzel in his fundamental work [3] writes: "The term thermocline has been defined variously, but correctly refers to the plane of maximum rate of decrease of temperature with respect to depth. An extensive discussion of these terms and their conceptual basis is given by Hutchinson $[26,27]$ '. If the mathematical approximation of the thermal structure (9) or (10) was known at that time, it could be possible to avoid the inadequacies of the thermocline positioning and hot discussions.

With the theoretical approximation formulas (9) and (10), it is not difficult to obtain the expression of the thermocline position $T_{t}(h)$ through the parameters of the thermodepth model. Indeed, the thermocline is defined as the inflection point of temperature dependence, which must satisfy the mathematical condition $T^{\prime}(h)=0$. By applying this condition to solution (10), we obtain:

$$
\begin{gathered}
T_{t}=T_{1}^{*}+\frac{T_{2}^{*}-T_{1}^{*}}{(1+v)^{1 / v}} \\
h_{t}=\frac{1}{a v} \ln \left(\frac{v}{a_{0}}\right) ; \quad a_{0} \equiv\left(\frac{T_{2}^{*}}{T_{0}}\right)^{v}-1 .
\end{gathered}
$$

The temperature and depth of the thermocline are determined by formulas (13), which can be compared with the experimental data. After approximating our measured experimental data, we get three basic parameters: $a=1.16721 \mathrm{~m}^{-1}, v=1.60418, T_{c}=16.568{ }^{\circ} \mathrm{C}$ and three additional: $a_{0}=2.9500 \cdot 10^{-3}, T_{0}{ }^{c}=16.546{ }^{\circ} \mathrm{C}$, $T_{1}^{*}=5.0497{ }^{\circ} \mathrm{C}$. Using their meanings, we obtain the thermocline depth and temperature values:

$$
T_{t}=11.39^{\circ} \mathrm{C}, \quad h_{t}=3.36 \mathrm{~m} .
$$

According to the comparison of experimental data and the theoretical approximation curve, the position of the thermocline is determined with sufficient accuracy (see Fig. 4).

It is interesting to trace the relationship between the temperature of the water surface $T_{0}$ and the thermocline $T_{t}$. The surface temperature $T_{0}$ has a higher oscillation

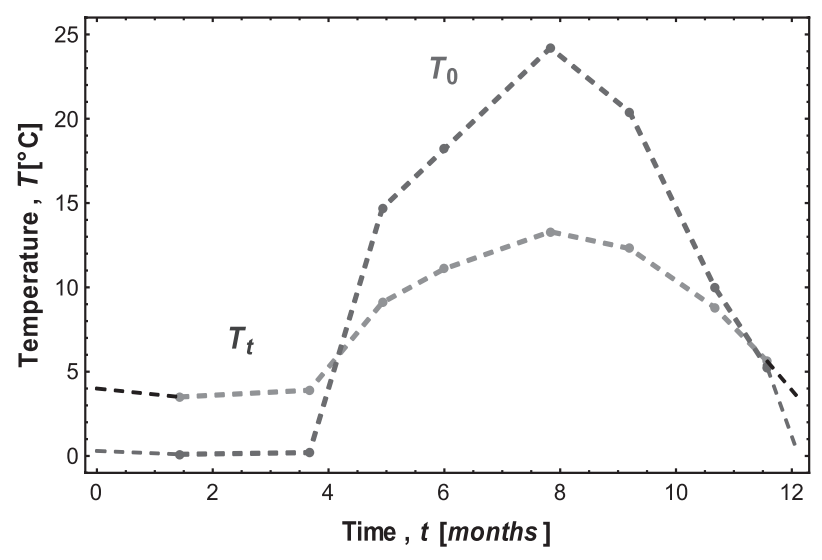

Fig. 5. Temperature change of Lake Tapeliai water surface $T_{0}$ and thermocline $T_{t}$ over the year.

amplitude than the temperature of the thermocline $T_{t}$. If the surface temperature varies from $T_{0}=0{ }^{\circ} \mathrm{C}$ in winter to $T_{0}=24.3{ }^{\circ} \mathrm{C}$ in summer, then the temperature of the thermocline is changing from $T_{t}=3 \div 4{ }^{\circ} \mathrm{C}$ in winter to $T_{t}=13.3^{\circ} \mathrm{C}$ in summer. As can be expected, their change takes place in a coherent way: the surface layers give their heat to the lower layers during the summer, and the inverse process takes place in winter (see Fig. 5). The Pearson temperature correlation coefficient value is $r=0.9916$.

As shown in Fig. 6, the position of the thermocline monotonically increases from $2.9 \mathrm{~m}$ at the end of April to $9.10 \mathrm{~m}$ in the second half of November and slightly decreases to $8.50 \mathrm{~m}$ at the end of March. The biggest changes of the thermocline temperature (from $8.50 \mathrm{~m}$ to $2.90 \mathrm{~m}$ ) take place in a rather short period - from March to the end of April.

In places where the two graphs cross over, the temperatures of the thermocline and sediment are the same. As shown in Fig. 6, this happens twice a year: around mid-March and close to November 18. This is an experimental confirmation that Lake Tapeliai is definitely dimictic.

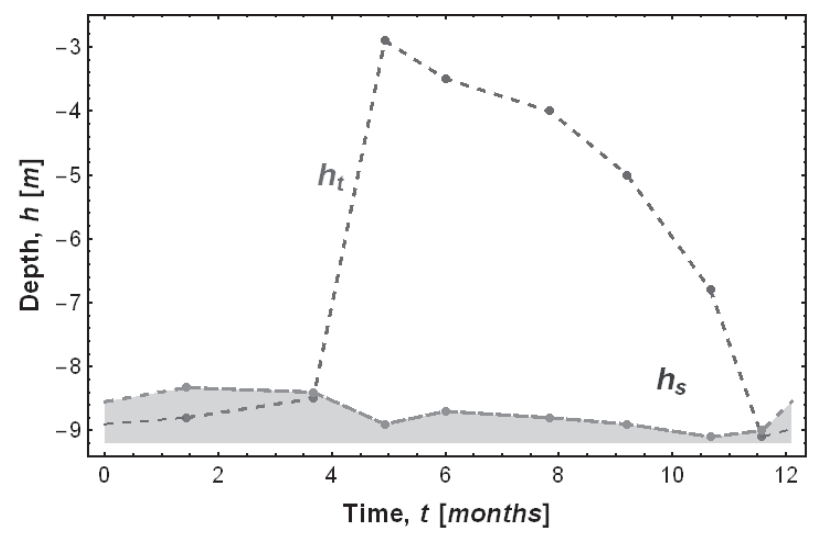

Fig. 6. Depth change over the year of water thermocline $h_{t}$ and of sediment $h_{S}$ of Lake Tapeliai. 
The depth of the sediments changes much less: from $9.10 \mathrm{~m}$ in October-November to $8.33 \mathrm{~m}$ in JanuaryFebruary.

\section{Discussion}

According to our measurements, the sediment layer forms a separate, important, independent part of Lake Tapeliai. We believe that lakes with sediment layers also are another special subclass of lakes. Eight lake models of different complexity were used, forced by identical meteorological variables and model parameters unified as far as possible given different formulations of processes. All models generally captured diurnal and seasonal variability of lake surface temperature reasonably well. However, some models were incapable of realistically reproducing temperature stratification in summer [30]. The effect of heat flux to bottom sediments can become significant for bottom temperatures. It also has a profound influence on the surface temperatures in autumn due to convective mixing, but not in summer when lake stratification is stable. Thus, neglecting sediments causes a summerautumn temperature difference in models lacking an explicit treating of sediments.

As follows from our measurements and the data of other authors, in sedimentary layers the density of suspended matter significantly differs from the density of water. In [31], a bulk density formula of lake water $\rho(T, C)$ is proposed:

$$
\rho(T, C)=\left(1+\frac{C}{\rho_{s}}\right) \rho(T)+C,
$$

where $C\left(\mathrm{~kg} / \mathrm{m}^{3}\right)$ is a suspended sediment density, $\rho_{s}\left(\mathrm{~kg} / \mathrm{m}^{3}\right)$ is the density of suspended particles, and $\rho(T)\left(\mathrm{kg} / \mathrm{m}^{3}\right)$ is the pure water density at temperature $T$ $\left({ }^{\circ} \mathrm{C}\right)$. This expression is very useful and can be used to simulate bottom processes. The authors used a particle density of $2730 \mathrm{~kg} / \mathrm{m}^{3}$, a value reported for sediment sampled in a proglacial lake in Nepal, since no data were available for the studied lakes.

Obtaining the thermal structure of lakes from the air is one of the promising and useful experimental techniques [32]. Remote observations of water temperature from aerial platforms are attractive: such platforms do not require shoreline access; they can be quickly and easily deployed and redeployed to facilitate repeated sampling and can rapidly move between target locations, allowing multiple measurements to be made during a single flight. However, they are also subject to well-known limitations, including payload, operability and a trade-off between the extent and density over which measurements can be made within restricted flight times. Despite some difficulties, we are sure that this technique has a great future.
Bathymetric measurements are usually approximated using complex mathematical packages that take into account a lot of external phenomena - not only vertical and horizontal, but also three-dimensional, for example, vortex or convective. Accordingly, mathematical models consist of differential partial derivatives of nonlinear equations with a multitude of model parameters [6]. We have succeeded in proposing a straightforward one-dimensional thermodepth model that effectively depends on two parameters: the nonlinearity parameter $v$ (see (1)) and the constant dimensionless temperature gradient $\gamma$ (see (2) and (3)). The maximum difference between experimental and theoretical data does not exceed $2.5 \%$. This may be associated with an abnormally large nonlinearity $v$.

\section{Conclusions}

Temperature value and distribution are of key importance for the course of biotic and abiotic processes occurring in rivers and lakes. Our research conclusions are as follows:

1. The isothermal temperature throughout the whole depth of the lake $T=5.2{ }^{\circ} \mathrm{C}$ settles around mid-March and close to November 18 .

2. The secondary epilimnion structure fluctuating from $20 \div 40 \mathrm{~cm}$ in March-April to $90 \div 120 \mathrm{~cm}$ in June-September was detected in March and lasted up to mid-October. No secondary epilimnion structure was observed in the period from October to February.

3. Based on the maximal differences between the experimental values and the prediction of our proposed theoretical model, the correctness of the model is estimated. The proposed thermodepth model of the lake with the accuracy of $97.5 \%$ describes Lake Tapeliai temperature dependence on its depth.

4. The changes of the thermocline temperature are clearly related to the changes of the lake surface temperature (Figs 4 and 5). This is confirmed by the relatively high Pearson correlation coefficient value $r=0.992$.

5. In our thermodepth model, the position of the thermocline can be determined theoretically. The model allows us to express the thernocline's position through the thermodepth model parameters (see formula (10)). The obtained theoretical values $T_{t}=11.39^{\circ} \mathrm{C}$ and $h_{t}=3.36 \mathrm{~m}$ are finely matching the experimental values (Fig. 4).

6. The sediment layer forms a separate, important, independent part of Lake Tapeliai.

We support numerous authors who devote special attention to sediments and even suggest distinguishing a separate group of lakes with sediments (see, e.g., [24] and references there).

Considering that the experimental approximation of the data of Lake Tapeliai was quite successful, there is a natural question about the limits of the proposed 
thermodepth model. A minimum of three important remarks should be made here:

a) Setting the limits is more complex than designing the model,

b) Our thermodepth model is not set against 3D models,

c) As shown by the long-term research results of other authors (see, e.g., [1, 2]), our thermodepth model could be applied to them, but this will become the object of further research.

\section{Acknowledgements}

We would like to thank Dr. doc. Nikolaj Tarasiuk for his valuable comments and advice. Thanks are also given to other laboratory colleagues for field and laboratory work assistance.

\section{Conflict of Interest}

The authors declare no conflict of interest.

\section{References}

1. WELCH P.S. Limnnology. London: Andesite Press, 558, 2017.

2. KILKUS K. Thermal structures of dimictic lakes. Vilnius: Vilnius University Press, 200, 2000 [In Lithuanian].

3. BRÖNMARK C., HANSSON L.-A. The Biology of Lakes and Ponds (Biology of Habitats Series) $3^{\text {rd }}$ Ed. Oxford University Press; London, 368, 2017.

4. HUTTER K., WANG Y., CHUBARENKO I. Physics of lakes. Vol. 1. Foundation of the mathematical and physical background. Springer, 483, 2011.

5. HUTTER K., WANG Y., CHUBARENKO I. Physics of lakes. Vol. 2: Lakes as Oscillators, Springer-Verlag Berlin Heidelberg, 715, 2011.

6. OMSTEDT A. Guide to Process Based Modeling of Lakes and Coastal Seas, $2^{\text {nd }}$ ed. Springer, Berlin, 273, 2016.

7. DAUBARIENE J., VALIUŠKEVIČIUS G. Lake Classifications used in Lithuania: System and Employment Possibilities. Geografija, 45 (2), 111, 2011 [In Lithuanian].

8. DAVIS M.D. On the Classification of Lake Basins, Palala Press, 125, 2016.

9. LANE A., NORTON M., RYAN S. Water Resources: A New Water Architecture, London: Wiley-Blackwell, 360, 2017.

10. BROUWER F.M., Integrated Environmental Modelling: Design and Tools (Studies in Operational Regional Science) Springer, Berlin, 273, 2011.

11. MOISEJENKOVA A., TARASIUK N., KOVIAZINA E., MACEIKA E., GIRGŽDYS A. ${ }^{137} \mathrm{Cs}$ in lake Tapeliai (Lithuania). Lithuanian Journal of Physics, 52 (3), 238, 2012.

12. TARASIUK N., MOISEJENKOVA A., KOVIAZINA E. On the mechanism of the enrichment in radiocesium of near-bottom water in Lake Juodis, Lithuania, Journal of Environmental Radioactivity, 101, 883, 2010.

13. VERHULST P.F. Notice sur la loi que la population poursuit dans son accroissement. Correspondance mathématique et physique, 10, 113, 2014.
14. BERGER-VACHON C., LAFUENTE A.M.G. Complex Systems: Solutions and Challenges in Economics, Management and Engineering. Springer; 43, 2017.

15. POLYANIN A.D., ZAITSEV V.F. Handbook of Nonlinear Partial Differential Equations $2^{\text {nd }} E d$. Chapman and Hall/ CRC; 1912, 2011.

16. CONSTANDA C., RIVA M. Integral Methods in Science and Engineering, Volume 1: Theoretical Techniques. Birkhäuser; 340, 2017.

17. ZHEN-GANG JI. Hydrodynamics and Water Quality, John Wiley \& Sons: New Jersey, 692, 2017.

18. ARNOLD V.I. Mathematical Understanding of Nature: Essays on Amazing Physical Phenomena and Their Understanding by Mathematicians. New York: American Mathematical Society, pp.167, 2014.

19. MICHEL A.N., HOU L. Stability of Dynamical Systems: On the Role of Monotonic and Non-Monotonic Lyapunov Functions (Systems \& Control: Foundations \& Applications), Birkhäuser: New York, 653, 2016.

20. MIŠKINIS P., VASILIAUSKIENE V. The analytical solutions of the harvesting Verhulst's evolution equation. Ecology Modelling, 360, 189, 2017.

21. ROSS J.V. A note on density dependence in population model. Ecological Modelling, 220, 3472, 2009.

22. DOMINGUEZ H., MUNOZ M.J.G. Water Extraction of Bioactive Compounds: From Plants to Drug Development. Elsevier; 530, 2017.

23. GULATI R.D., ZADEREEV E.S. Ecology of Meromictic Lakes (Ecological Studies) Springer; 405, 2017.

24. TARASIUK N., MOISEJENKOVA A., PEČIULIENE M., JASAITIS D., GIRGŽDYS A. Peculiarities of Thermal Regime Formation of Near-Bottom Lake Water, Pol. J. Environ. Stud., 24 (6), 2655, 2015.

25. TUNDISI J.G., TUNDISI T.M. Limnology. CRC Press. Taylor and Francis Group, pp. 865, 2011

26. SEN Z. Applied Hydrogeology for Scientists and Engineers. CRC Press; 435, 2017.

27. LANE A., NORTON M. Water Resources: A New Water Architecture. Wiley-Blackwell; 334, 2017.

28. PTAK M., CHOIŃSKI A., PIEKARCZYK J., PRYŁOWSKI T. Applying Landsat Satellite Thermal Images in the Analysis of Polish Lake Temperatures. Pol. J. Environ. Stud., 26 (5), 2159, 2017.

29. DUNALSKA J. Impact of limited water flow in a pipeline on the thermal and oxygen conditions in a lake restored by hypolimnetic withdrawal method. Pol. J. Environ. Stud., 12 (4), 409, 2003

30. STEPANENKO V.M., MARTYNOV A., JOHNK K.D., M. SUBIN Z., PERROUD M., FANG X., BEYRICH F., MIRONOV D., GOYETTE S. A one-dimensional model intercomparison study of thermal regime of a shallow, turbid midlatitude lake. Geoscientific Model Development, 6, 4, 2013.

31. SUGIYAMA S., MINOWA M., SAKAKIBARA D., SKVARCA P., SAWAGAKI T., OHASHI Y., NAITO N., CHIKITA K. Thermal structure of proglacial lakes in Patagonia. Journal of Geophysical Research: Earth Surface, 121, 12, 2016

32. CHUNG M., DETWEILER C., HAMILTON M., HIGGINS J., ORE J.P., THOMPSON S. Obtaining the Thermal Structure of Lakes from the Air. Water, 7, 11, 2015. 